13 meridional arc (.001 meters)

Range and Interval

$A(10 \mathrm{D}, 8 \mathrm{~S}), B(10 \mathrm{D}, 8 \mathrm{~S})$

$0\left(1^{\prime}\right) 90^{\circ}$

$C(15 \mathrm{D}, 7 \mathrm{~S}), D(12 \mathrm{D}, 4 \mathrm{~S})$,

$0\left(1^{\prime}\right) 90^{\circ}$

$N, R$ (both .001 meters)

$0\left(1^{\prime}\right) 90^{\circ}$

$0\left(1^{\prime}\right) 90^{\circ}$

16 military grid coordinates from U.S.C. \& G.S.S.P. no. 59

$X, Y$ (both .1 yard) Lat., Long. of U. S.

$5^{\prime}$ intersections

17 latitude transformation tables geometric-

isometric: isometric-geodetic for following

spheroids: Clarke 1866, 1880, 1860 ; Hayford,

Bessel, Everest

geodetic-authalic: authalic-geodetic for Clarke 1866

$0\left(1^{\prime}\right) 90^{\circ}$

$0\left(1^{\prime}\right) 90^{\circ}$

\title{
U. S. NAVAL OBSERVATORY
}

\begin{tabular}{clc} 
File & \multicolumn{1}{c}{ Function and Accuracy } & Range and Interval \\
1 & $\sin x(7 \mathrm{D}), \cos x(7 \mathrm{D}), \tan x(7 \mathrm{D})$ & $0(0: 01) 90^{\circ}$ \\
2 & $1 / x(6 \mathrm{D})$ & $1(.001) 4$ \\
& & $4(.01) 10$ \\
3 & $\log ^{-1} x(8 \mathrm{D})$ & $0(.001) 1$ \\
4 & $\operatorname{hav}^{-1} x($ about $0: 001)$ & 0 to $25^{\circ}$ \\
$\mathbf{5}$ & $\sin x(8 \mathrm{D}), \cos x(8 \mathrm{D})$ & $0(0: 01) 90^{\circ}$
\end{tabular}

Special tables for astronomical work.

VEGA AIRCRAFT CORPORATION

File

$1 \log x(8 \mathrm{D}), \Delta \log x(8 \mathrm{D}), 1 /(\Delta \log x)$

$10000(1) 100000$

W. J. E.

\section{RECENT MATHEMATICAL TABLES}

211[A].-W. VRIEsendorP, The Calculating Dictionary, Utrecht, L. E. Bosch \& Zoon, printer, for the author, 1937. [1003 p.], $13.5 \times 26.7 \mathrm{~cm} .17 .5$ Dutch florins.

This Dictionary contains the multiplications up to $999 \times 999$, except multiples of ten. There are two pages of examples showing applications of the volume in obtaining the products of larger numbers. On each page headed 2, 3, ., 999 are given 900 products. The Dutch edition has the title De Rekendictionnaire Tabellen bijeengebracht ten dienste van handel, industrie, administratie en onderwijs.

There is no reference to any other work offering the same tabular information, and readily available in 1937, such as: A. L. Crelle, Calculating Tables, Berlin, 1930 which has gone through many editions, since. the first two-volume edition in 1820 , including one by an insurance company in Japan (1913).

212[D].-M. J. Buerger \& Gilbert E. Klein, "Correction of X-ray intensities for Lorentz and polarization factors," Journal of Applied Physics, v. 16, July, 1945, p. 414-418. $20 \times 26.6 \mathrm{~cm}$.

Four-place tables are given for the following functions: $2 \sin 2 \theta /\left(1+\cos ^{2} 2 \theta\right)$ and $2 /\left(1+\cos ^{2} 2 \theta\right)$, for the argument $\sin \theta=0(.001) .999$. 
213[D, M].-Leon Beskin, "General circular ring analysis," Aircraft Engineering, v. 17, May, 1945, p. 127-132. $24.5 \times 31 \mathrm{~cm}$.

There are tables of $\phi(\theta)=[1 / 2 \pi]\left[\theta(1+\cos \theta)-\frac{1}{2}(3 \sin \theta)\right], \phi^{\prime}(\theta)=[1 / 2 \pi][-\theta \sin \theta$ $\left.-\frac{1}{2} \cos \theta+1\right], \phi^{\prime \prime}(\theta)=[1 / 2 \pi]\left[-\frac{1}{2} \sin \theta-\theta \cos \theta\right], \phi^{\prime \prime \prime}(\theta)=[1 / 2 \pi]\left[-\frac{1}{2}(3 \cos \theta)+\theta \sin \theta\right]$, $\psi(\theta)=\phi(\theta)+\phi^{\prime \prime}(\theta)=[1 / 2 \pi][\theta-2 \sin \theta], \quad \psi^{\prime}(\theta)=\phi^{\prime}(\theta)+\phi^{\prime \prime \prime}(\theta)=[1 / 2 \pi][1-2 \cos \theta]$, $\psi^{\prime \prime}(\theta)=\phi^{\prime \prime}(\theta)+\phi^{\prime \prime \prime \prime}(\theta)=[1 / \pi] \sin \theta$, to $5 \mathrm{D}, \theta=0\left(5^{\circ}\right) 180^{\circ}$. Graphs of these seven functions are also set forth. Furthermore, there are tables and graphs of the following nine functions:

$\Gamma(a)=[1 / 2 \pi]\left[\cos a\left(\pi^{2} / 6-23 / 8-\frac{1}{2} \pi a+a^{2} / 4\right)+\frac{1}{2}(\pi-a) 3 \sin a+\pi^{2} / 3-2-a \pi+\frac{1}{2} a^{2}\right]$,

$\Gamma_{1}(a)=[1 / 2 \pi]\left[(\pi-a)(\cos a-1)-\sin a\left(\pi^{2} / 6-11 / 8-\frac{1}{2} \pi a+a^{2} / 4\right)\right]$,

$\Gamma_{2}(a)=[1 / 2 \pi]\left[-\cos a\left(\pi^{2} / 6-3 / 8-\frac{1}{2} \pi a+a^{2} / 4\right)-\frac{1}{2}(\pi-a) \sin a+1\right]$,

$\Gamma_{3}(a)=[1 / 2 \pi] \sin a\left(\pi^{2} / 6+1 / 8-\frac{1}{2} \pi a+a^{2} / 4\right)$,

$\Gamma_{4}(a)=[1 / 2 \pi]\left[\cos a\left(\pi^{2} / 6+1 / 8-\frac{1}{2} \pi a+a^{2} / 4\right)-\frac{1}{2}(\pi-a) \sin a\right]$,

$\Lambda(a)=[1 / 2 \pi]\left[\cos a\left(\pi^{2} / 6+13 / 8-\frac{1}{2} \pi a+a^{2} / 4\right)+\frac{1}{2}(\pi-a) \sin a\right]$,

$\Delta(a)=[1 / 2 \pi]\left[-\frac{1}{2}(5 \cos a)+(\pi-a) \sin a+\pi^{2} / 3-1-a \pi+\frac{1}{2} a^{2}\right]$,

$E(a)=[1 / 2 \pi]\left[-2 \cos a+\pi^{2} / 3-a \pi+\frac{1}{2} a^{2}\right]$,

$\Omega(a)=[1 / \pi] \cos a, a=0\left(5^{\circ}\right) 180^{\circ}$, all to $5 \mathrm{D}$, except $\Gamma(a)$ and $\Gamma_{1}(a)$, to $6 \mathrm{D}$.

$\Gamma(a)=\int_{0}^{2 \pi} \phi(\theta) \phi(\theta+a) d \theta, \quad \Gamma_{4}(a)=\int_{0}^{2 \pi} \phi^{\prime \prime}(\theta) \phi^{\prime \prime}(\theta+a) d \theta_{4}$

$\Delta(a)=\int_{0}^{2 \pi} \phi(\theta) \psi(\theta+a) d \theta$, etc.

214[E].-H. W. Holtappel, Tafels van $e^{x}$. Groningen, Noordhoff, 1938, xxxi, 132 p. $24 \times 29.5 \mathrm{~cm} .6 .00$ Dutch florins.

The book under review provides a very useful table of the exponential function $e^{z}$, both for positive and negative values of the argument, over ranges which hitherto had been accessible only.with difficulty in existing tables. In the preface, which is published in Dutch, English, French, German, and Italian, the author explains the origin of the present volume.

Intrigued by the apparent scarcity of tables of the exponential function the author made a cursory survey of the literature and discovered the existence of the extensive computations of F. W. Newman: "Table of the descending exponential function to twelve or fourteen places of decimals," Cambridge Phil. So., Trans., v. 13, 1883, p. 145-241. Unfortunately he failed to find Newman's second paper: "Table of the exponential function $e^{*}$ to twelve places of decimals," Cambridge Phil. So., Trans., v. 14, 1889, p. 237-249; see N43 in this issue. Hence he says: "Seeing that the Encyclopadia Britannica, 1929 mentioned Mr. Newman's tables as the most extensive published concerning $e^{x}$, I was convinced that a table as desired was not in existence. I therefore resolved to compile one myself."

The author incorporated the values of $e^{-x}$ from Newman's table, which he checked and found accurate except for an occasional value in the 12th decimal place. His principal table, namely values of the exponential over the range $x=0(.001) 9.999$, he constructed from 13-place values over the range $x=0(.01) 9.99$ by means of the formula

$$
e^{x+h}=e^{x}\left(1+h+\frac{h^{2}}{2 !}+\frac{h^{3}}{3 !}+\cdots\right),
$$

and in this way "built up the whole as one linked chain."

His check of Newman's table and of his own computation was effected through the formula

$$
\left(e^{n}-1\right) /(e-1)=e^{n-1}+e^{n-2}+\cdots \cdot
$$

With this introduction explaining the origin of the tables we may turn to their actual contents.

Table I, which is the author's principal table, gives in adjoining columns the values of $e^{x}$ and $e^{-x}$ to 10D for $x=0(.001) 9.999$.

Table IIA gives values of $e^{x}$ for $x=1(1) 24$ to $20 \mathrm{D}$ and $e^{-x}$ over the same range from 
16 to 22D. Tables IIB, C, and D tabulate the same functions over the ranges $x=.1(.1) .9$; $.01(.01) .09 ; .001(.001) .009$, the first function to 24 or $25 \mathrm{D}$ and the second to $18 \mathrm{D}$.

Tables IIIA, B, C give values of $e^{x}$ over the following ranges: $x=[0(.1) 9.9 ; 18 \mathrm{D}]$, $x=[0(.001) .099 ; 24 \mathrm{D}], x=[0(.001) .999,17 \mathrm{D}]$.

Tables IIID, E, and F tabulate $e^{y}$, where $y$ is successively $x \cdot 10^{-6}, x \cdot 10^{-9}$, and $x \cdot 10^{-12}$ over the range $x=[0(1) 999 ; 20 \mathrm{D}]$.

Table IV provides to $18 \mathrm{D}$ the first ten multiples of $M$ and $1 / M$, where $M=\log e$.

The errors of this volume are discussed elsewhere in this issue, MTE 68.

In the year following the publication of the work under review, the extensive tables of the NYMTP made their appearance. These cover the following range: For $e^{x}$, $x=[0(.0001) 1 ; 18 \mathrm{D}], x=[1(.0001) 2.5(.001) 5 ; 15 \mathrm{D}]$, and $x=[5(.01) 10 ; 12 \mathrm{D}] ;$ for $e^{-x}$, $x=[0(.0001) 2.5 ; 18 \mathrm{D}]$. It is thus seen that, to 10 decimal places, the Holtappel tables, even now, extend the range of values tabulated, especially for the exponent of descending argument.

H. T. D.

215[E].-NYMTP (A. N. Lowan, technical director), Tables of the Exponential Function $e^{x}$, New York, 1939, xviii, 535 p. $21 \times 27 \mathrm{~cm}$. Reproduced by a photo-offset process. Sold by the U. S. Bureau of Standards, Washington, D. C. $\$ 2.00$.

This volume provides accurate tables of the function $e^{x}$ for small intervals of the argument. The frequent use of the exponential function in a wide variety of computational work makes these tables extremely valuable as they give a complete tabulation of the function over a large range of values. An account of the care with which the tables were designed and checked is set forth in the Introduction.

The first four tables give the values of the ascending exponential from 0 to 10 with varying intervals and number of decimals. The ranges are as follows: $x=[0(.0001) 1 ; 18 \mathrm{D}]$, [1(.0001) $2.5(.001) 5 ; 15 \mathrm{D}]$, and $[5(.01) 10 ; 12 \mathrm{D}]$. $18 \mathrm{D}]$

The values of the descending exponential are given for the range $-x=[0(.0001) 2.5$;

Besides these main tables, there are three tables to cover more adequately the interval about zero, and certain integral values of $x$, nameiy: $\pm x=[0(.000001) .0001 ; 18 \mathrm{D}]$, [1(1) $100 ; 19 \mathrm{~S}]$, and [1(1)9.10-p;18D], $p=7(1) 10$.

It is unfortunate that the tables for $e^{-x}$ were not extended beyond $x=2.5$. The values of the function for arguments larger than 2.5 can, of course, be calculated by using the supplementary integer table. To be sure there are Newman's tables ${ }^{1}$ for $x=[0(.001) 15.349$; 12D], [15.350(.002)17.3(.005)27.635; 14D], and [.1(.1)37; 18D]. However, it would have been a decided advantage to have had the complete tables collected into one volume.

Univ. California,

EvELYN FIX

Berkeley

I F. W. Newman, "Table of the descending exponential function to twelve or fourteen places of decimals," Cambridge Phil. So., Trans., v. 13, 1883, p. 145-241.

216[E, L].--National Defense Research Committee, Tables for Solutions of the Wave Equation for Rectangular and Circular Boundaries having Finite Impedance, prepared by A. N. Lowan for the NYMTP, \& P. M. Morse, H. Feshbach \& E. Haurwitz for the M.I.T. Underwater Sound Laboratory. Report dated June 1945. Printed from manuscript, ii, 52 leaves, and 7 plates on only one side of each leaf, by the photo-offset process. These tables are available only to certain Government agencies and astivities.

For rectangular boundaries the wave equation can be separated into differential equa- 
tions of the form

$$
d^{2} \psi / d x^{2}+k^{2} \psi=0 .
$$

The boundaries for the $x$ coordinate can be placed at $x=0$, and $x=a$. The boundary condition at $x=a$ will be defined by the equation

$$
\psi=z x(d \psi / d x), \quad(x=a),
$$

where $z=r e^{i \phi}$ is proportional to the impedance of the boundary at $x=a$. The solution of the problem depends on the nature of the boundary conditions at $x=0$.

$$
\text { Case I. Boundary condition at } x=0 \text { is } \psi=0 \text {. }
$$

In this case the solution used is

$$
\psi=\sinh (i k x)=\sinh (w x / a),
$$

where $w=i k a$. The boundary condition at $x=a$, given by the equation (2), then gives rise to the equation

$$
(1 / w) \tanh w=z=r e^{i \phi},
$$

where

$$
w=R-i I=\pi \beta e^{-i \phi} .
$$

The values of $R$ and $I$, for each of four branches are given, Table I, p. 7-26, as functions of $r$ and $\phi, r=[0(.01) .2(.02) .5(.05) 1(.1) 2(.2) 5(.5) 10 ; 3 \mathrm{D}], \phi=0\left(10^{\circ}\right) 180^{\circ}$. After p. 48 is a large folding plate $(18 \times 67 \mathrm{~cm}$.) containing a graph of $(4)$. There are also two other plates of this function, $w=\pi \beta e^{-i \phi}$, First Branch; and, $z=r e^{i \phi}$, Second Branch.

\section{Case II. Boundary condition at $x=0$ is $d \psi / d x=0$.}

In this case the solution used is

$$
\psi=\cosh (i k x)=\cosh (w x / a), \quad w=i k a .
$$

This gives rise to the equation

$$
(1 / w) \operatorname{coth} w=z=r e^{i \phi} .
$$

Solutions of this equation for

$$
w=R-i I=\pi \beta e^{-i \phi},
$$

as a function of $r$ and $\phi$, are given, as above, in plots and Table II, p. 28-47, and after p. 51 .

Both of these transformations have branch points in the complex plane; their position can be determined by setting $d z / d w=0$. For Case I, this corresponds to setting $2 w=\sinh (2 w)$, and for Case II it corresponds to setting $2 w=-\sinh (2 w)$. The positions of the first five branch points for each case are given on p. 4 .

The wave equation determining the propagation of circularly symmetrical waves down cylindrical ducts, with a circular cross section, is (the corresponding equation of the publication is in unintelligible form)

$$
\frac{1}{\rho} \frac{d}{d \rho}\left(\rho \frac{d \psi}{d \rho}\right)+k^{2} \psi=0 .
$$

The solution of this equation is

$$
\psi=J_{0}\left(i w_{\rho} / a\right),
$$

$w=i k a=R-i I, a$ being the radius of the circular cross section.

Taking account of the boundary condition (2) in this case, we are led to the equation

$$
i J_{0}(i w) /\left[w J_{1}(i w)\right]=z=r e^{i \phi} .
$$

The branch points of this transformation are determined by setting $d z / d w=0$, which 
yields

$$
J_{1}(i w)= \pm i J_{0}(i w) .
$$

Three solutions of this equation, determined by interpolation, are given (p. 5). There is also a chart of the transformation (9), where, as in the other charts, 4 heavy dotted lines divide different branches of the transformation.

In Tables I and II are various subtables of branch cuts and branch points. In the neighborhood of the branch points the accuracy of these tables is not better than $1 \%$.

An errata list, recently distributed by P. M. Morse, indicates a number of errors in the tables.

$$
\text { R. C. A. }
$$

217[F].-Polnoe Sobranie Sochineniz P. L. Chebysheva [Complete Collection of Works by P. L. Chebyshev], Volume I: Teoriva Chisel [Theory of Numbers]. Moscow and Leningrad, Academy of Sciences, 1944, 342 p. + portrait frontispiece. $17 \times 26 \mathrm{~cm}$. 20 roubles paper; 23 roubles bound. Edition of 5000 copies.

The Works (Sochineniva-Oeuvres) of Pafnutir L'vovich Chebyshev (1821-1894) were edited by A. A. Markov \& N. I. Sonin, and published by the Academy of Sciences at St. Petersburg, 1899-1907, in two editions, one entirely in Russian, 2v., the other entirely in French, 2v., large handsome volumes of over $700 \mathrm{p}$. each. These two editions were made possible when a brother of Chebyshev gave 5000 roubles towards the cost of publication, coupled with the condition as to the two editions. The translations into Russian of Chebyshev's papers originally written in French, and into French of papers originally written in Russian were mainly carried out by Chebyshev's pupils. These volumes did not include Chebyshev's doctoral dissertation on the Theory of Congruences (1849), or his master's thesis Essay of Elementary Analysis on the Theory of Probabilities (1845), or his Lectures on the Theory of Probability (1879-80), published in 1936. Since the original SochinenizaOeuvres are now difficult to obtain, the Academy of Sciences decided to celebrate the fif tieth anniversary of Chebyshev's death by publishing a more adequate Russian edition of his works, in 5 volumes to include his dissertations and unpublished papers, as well as a complete list of photographs of mechanisms constructed by him. Volume I, containing his work on the Theory of Numbers, and edited by I. M. Vinogradov \& B. N. Delone, is the one before us for review; v. II-III are to contain Chebyshev's work on Analysis; v. IV, that on mechanisms; and v. V, other works, and historical and biographical material. The new edition is also to contain short commentaries indicating subsequent development of various themes of Chebyshev in contemporary science.

The editorial committee appointed by the president of the Academy was as follows: S. N. Bernstein (Chairman), N. G. Bruenich, I. M. Vinogradov, A. N. Krilov, L. S. Leł̌benzon, S. L. Sobolev, N. N. ArmobolevskiY,, B. N. Delone, and V. L. Goncharov.

Now for the contents of v. I. The frontispiece and biographical sketch by Posse (p. 5-9), are the same as in v. 2 of the Sochineniza. Then comes the sixth edition of the Theory of Congruences, ${ }^{1}$ p. 10-172, with Tables, p. 311-339. These four Tables are as follows:

(i) Prime numbers less than 6000 ;

(ii) Primitive roots and indices of all prime numbers modulo $\mathrm{p}<200$; these tables were taken from M. Ostrogradskil (1838), but were given much more extensively by JACOBI, in his Canon Arithmeticus, 1839, p < 1000;

(iii-iv) Linear divisors of the quadratic form $x^{2} \pm a y^{2}$ for all values of $a$ from 1 to 101 .

In his Guide to Tables in the Theory of Numbers, Washington, D. C., 1941, D. H. L. lists (p. 132-133) numerous errors in (iii-iv) of editions (a) and (f), but states that edition (c) is without error. It is therefore with some surprise that we note the following earlier errors are also in (d), the present edition: 


$\begin{array}{ccc}\text { Form } & \text { Insert } & \text { Delete } \\ x^{2}+42 y^{2} & 157 & 159 \\ x^{2}+66 y^{2} & 71 & 77 \\ x^{2}+86 y^{2} & 87 & 89 \\ x^{2}+89 y^{2} & 345 & 354 \\ x^{2}+101 y^{2} & 309,317,333 & 305,321 \\ x^{2}-38 y^{2} & 21,131 & 23,129 \\ x^{2}-62 y^{2} & 107,141 & 103,145\end{array}$

There is also an error in (ii), which was correct in edition (c), namely:

$$
p=13 \text {, T. I, argument } 12 \text {, for }- \text {, read } 6 \text {. }
$$

Then in the rest of the volume under review are 8 papers (p. 173-282), a demonstration of a theorem of Chebyshev based on a fragment found among his papers, edited by Markov (p. 283-284), and Commentary by Delone (p. 285-309). The paper on Quadratic Forms (p. 208-228) contains a table (p. 220-222) of quadratic forms $\pm\left(x^{2}-2 y^{2}\right), \cdots, \pm\left(x^{2}-33 y^{2}\right)$, with limits of $x$ and $y$, and linear forms of N. This table had appeared earlier in J. d. Math., s. 1 , v. 16,1851 , p. $273-274$, and in Sochinenira-Oeuvres, v. 1, 1899, p. 88-89.

R. C. A.

1 There are now the following six editions of the Theory of Congruences:

(a) Teoriıâ Sravneniı̌ (Theory of Congruences), Diss. St. Petersburg, St. Petersburg, 1849, ix, iii, $281 \mathrm{p}$.

(b) Second ed., St. Petersburg, 1879, viii, iii, iii, 223, 26 p.

(c) Third ed., St. Petersburg, 1901, xvi, 279 p.

(d) Fourth ed., Moscow-Leningrad, 1944, reviewed above.

(e) Theorie der Congruenzen, German transl. by H. Schapira, Berlin, 1889, xviii, 314, 32 p.

(f) Teoria delle Congruenze, Italian transl., with additions and a note, by I. Massarini, Rome, 1895, xvi, 295 p.

\section{8[H].-Henry A. Nogrady, A New Method for the Solution of Cubic} Equations, Ann Arbor, Edwards Bros., 1936, iv, 22, ii, xxx p. $13.5 \times 21$ cm. Lithoprinted. $\$ 1.25$.

Given a cubic equation with numerical coefficients,

$$
a x^{3}+b x^{2}+c x+d=0,
$$

the substitution $x=y-b /(3 a)$ transforms equation (1) into

$$
y^{3}+p y+q=0,
$$

where $p=\left(3 a c-b^{2}\right) /\left(3 a^{2}\right), q=2 b^{3} /\left(27 a^{3}\right)-b c /(3 a)+d / a$. Applying the transformation $y=q z / p$ to equation (2), we get

$$
z^{3}+n z+n=0,
$$

where $n=p^{3} / q^{2}$. If $z_{1}$ is one of the three roots of (3) $n=-z_{1}^{3} /\left(z_{1}+1\right)$. Hence, while $z_{1}$ increases from -1.5 to $-1, n$ decreases from -6.75 to $-\infty$; while $z_{1}$ increases from -1 to $0, n$ decreases from $+\infty$ to 0 ; while $z_{1}$ increases from 0 to $3, n$ decreases from 0 to -6.75 . Thus for $+3>z_{1}>-1.5, n$ may take on any value from $+\infty$ to $-\infty$.

In the thirty-page table, for each $z_{1}$ (except -1 ) in this range, at interval .001 , the corresponding value of $n$ is given to $6 \mathrm{D}$ (except for a few values to a larger number of decimal places). Thus, having reduced a given cubic equation to the form (3), an approximate three-place value of $z_{1}$, corresponding to the resulting $n$, can be read off from the table. Then the other roots of (3), real or imaginary, are found by the formulae

$$
z_{2}=\frac{1}{2} z_{1}\left\{-1+\left[\left(z_{1}-3\right) /\left(z_{1}+1\right)\right]^{3}\right\}, \quad z_{3}=\frac{1}{2} z_{1}\left\{-1-\left[\left(z_{1}-3\right) /\left(z_{1}+1\right)\right]^{3}\right\} .
$$

The author shows that if $z_{1}+d$ is the true value of $z_{1}$ a six-place value for $z_{1}$ may be found by one or more applications of the formula $z_{1}+d=\left(2 z_{1}^{3}-n\right) /\left(3 z_{1}^{2}+n\right)$.

A tiny 6-page Pocket Tables for Cubics. A Systematic Method for Algebraic Treatment of Cubic Equations, 1933, by David KATz, patent attorney, was reviewed in Scripta Mathematica, v. 2, 1934, p. 379. The cubic is reduced to the form $z^{3}+z=D$.

The numerical solution of cubic equations, with tables, is also set forth by F. EMDE, 
Tables of Elementary Functions, 1940, p. 38-47, see $M T A C$, p. 384-385. The standard form here is $y^{3}+2=3 p y$. If only one root is real the roots are $y_{1}=y^{\prime}+i y^{\prime \prime}=s i^{\sigma}$, $y_{2}=y^{\prime}-i y^{\prime \prime}=s i^{-\sigma}, y_{3}=-2 y^{\prime}=-2 s \cos \sigma$. For $3 p=-9.9(.1)+1(.05) 2(.02) 2.8(.01) 3$, Emde gives $y^{\prime}, y^{\prime \prime}, s$, to $4 \mathrm{~S}$ or $5 \mathrm{~S}$, and $\sigma$ to $4 \mathrm{D}$ or $5 \mathrm{D}$. When all the roots are real, the roots $y_{1}, y_{2}, y_{3}$ are given to $4 \mathrm{~S}$ or $5 \mathrm{~S}$, for $3 p=3(.01) 3.2(.02) 4(.05) 5(.1) 10(.5) 15$. See also JAHNKE \& EMDE, Tables of Functions . . ., 1943 and 1945 (MTAC, p. 386), Addenda, p. 20-30.

Tables for the solution of the trinomial equations $x^{m+n} \pm e x^{m} \pm f=0$, are given in S. GUNDELFINGER, Tafeln zur Berechnung der reellen Wurzeln sämtlicher trinomischen Gleichungen ..., Leipzig, 1897.

$$
\text { R. C. A. }
$$

219[J, L, M].-I. M. Ryzhik, Tablitsy Integralov, Summ, Riadov i Proizvedeniน [Tables of Integrals, Sums, Series and Products], Leningrad, OGIZ, 1943.400 p. $14.6 \times 21.5 \mathrm{~cm}$. 25 roubles, paper bound. Edition of 3000 copies.

Since the author felt that no single Soviet or foreign work presented an adequate collection of formulae in integrals, sums, series, and products, for the research mathematician and engineer, the present work with over 5000 formulae was compiled to fill the need. While the work is primarily for such workers, in order to extend the circle of people who might profit from its use, a concise body of indispensable information, supplementing the formulae, is given near the end of the work (p. 339f).

The main sources for the choice of formulae were, (a) for indefinite and elliptic integrals, W. LÁsKa, Sammlung von Formeln der reinen und angewandten Mathematik, Braunschweig, 1888-1894; (b) for definite integrals Bierens de HAAN, Tables d'Intégrales Définies, Amsterdam, 1858-64, and Nouvelles Tables d'Intégrales Définies, Leyden, 1867; (c) for sums, series, and products, E. P. Adams, Smithsonian Mathematical Formulae and Tables of Elliptic Functions, Washington, 1922.

The author tells us that the classification of the material presented great difficulties. The arrangement of the indefinite integrals is essentially that given by G. H. Hardy in his Integration of Functions of a Single Variable (Cambridge, second ed., 1928); the author found it desirable, however, to assemble the material on elliptic integrals and functions according to his own arrangement, in Part II. The classification of definite integrals is, with minor modifications, that of Bierens de Haan.

Great attention was paid to special functions, particularly elliptic, cylindrical, spherical. The book contains many formulae pertaining to these functions. Among others are given also formulae of a function introduced by the author namely (p. 296):

$$
\begin{aligned}
s(x, y)=\Gamma(x+y-1) / \Gamma(x) \Gamma(y)=\lim _{n \rightarrow \infty} s(x, n) s(y, n) / s(x+y-1, n) \\
=\prod_{k=0}^{\infty} \frac{(x+k)(y+k)}{(x+y-1+k)(1+k)} .
\end{aligned}
$$

The introduction of this function made it possible to simplify and to generalize a number of formulae.

An outline of the contents is as follows:

Part I: Indefinite Integrals (p. 1-80)

1. General formulae; 2. Fundamental integrals; 3. Rational functions; 4. Irrational

functions; 5. Trigonometric functions; 6. Exponential functions; 7. Logarithmic

functions; 8 . Inverse trigonometric functions; 9 . Hyperbolic functions.

Parl II: Elliptic Integrals and Functions (p. 81-111)

1. Fundamental formulae; 2. Elliptic integrals; 3. Integrals of elliptic functions;

4. Elliptic integrals and Weierstrass functions.

Part III: Definite Integrals (p. 112-239)

1. General formulae; 2. Integrals of elementary functions; 3. Special functions;

4. Multiple integrals. 
Part IV: Sums, Series, Products (p. 240-338)

1. Numerical series and products; 2. Fundamental series and products (elementary functions); 3. Special functions.

The theoretical section on Applications (p. 339-387) has the following subheadings:

1. Integration in finite form; 2. Approximate methods of integration; 3. Multiple integrals; 4. Convergence of series and products; 5 . Classification of series and products; 6. Transformation of series; 7. Connection between series and products; 8 . Methods of summation of power series.

Then follow four numerical tables (p. 388-391) of frequent occurrence: (1) (2n-1)!!/ $(2 n) ! !=s(n+1, n+1) / 2^{2 n}, \quad n=1(1) 15$; coefficients in the expansion of $(1+x)^{!}$; (2) $(2 n-1) ! ! /[(2 n) ! !(2 n+1)]=s(n+1, n+1) /\left[2^{2 n}(2 n+1)\right], n=1(1) 15$;

(3) $(2 n-1) ! ! /(2 n+2) ! !=s(n+2, n+2) / 2^{2 n+2}(2 n+1), n=1(1) 14$;

(4) $(2 n-1) ! ! /[(2 n+2) ! !(2 n+3)]=s(n+1, n+1) /\left(2^{2 n+1} s(2 n+2,3)\right], \quad n=1(1) 14$. All of these numerical values are given as fractions and to 10 decimal places; up to $n=10$, (1) and (3), in decimal forms, are given in P. BARLow, New Mathematical Tables, London, 1814 , p. 256; up to $n=15$ the exact decimal values of (1) are given in J. H. LAMBERT, Supplementa Tabularum, Lisbon, 1798, p. 198; also German ed., 1770, p. 210.

Of the 47 titles in the Bibliography (p. 392-393), no dates are given for 41 . Most of the titles are well-known works, and it is of interest that only Russian editions are mentioned for works of Courant, La Vallée-Poussin, Euler, Goursat, Granville, Scarborough, Whittaker \& Robinson, and Whittaker \& Watson. Gray \& Matthews' Treatise on Bessel Functions, L. B. W. Jolley's Summation of Series, B. O. Peirce's $A$ Short Table of Integrals, I. Todhunter's An Elementary Treatise on Laplace's Functions, Lamé's Functions and Bessel's Functions, and Watson's A Treatise on the Theory of Bessel Functions, are naturally included in the list. The only items unknown to the reviewer were two Russian works:

Nina K. BARY, Theory of Series,

I. M. Ryzhiк, Special Functions.

Miss Bary has been a professor of mathematics at the Univ. of Moscow since 1932.

A somewhat detailed index of the formulae fills p. 394-400.

The work is undoubtedly one of considerable value for any mathematician to have at hand.

R. C. A.

220[L].-K. E. BIsshopp, "Lateral bending of symmetrically loaded conical discs," Quarterly Appl. Math., v. 2, Oct. 1944, p. 214-217. $17.6 \times 25.4$ cm. See RMT 202.

The calculation of the deflection coefficients and stress coefficients depends upon the hypergeometric functions

$$
\begin{aligned}
& G_{1}(x)=G_{1}(1-x)=F\left\{\frac{1}{2} a, \frac{1}{2} b ; 1 ;(1-2 x)^{2}\right\}, \\
& G_{2}(x)=-G_{2}(1-x)=(1-2 x) F\left\{\frac{1}{2} a+\frac{1}{2}, \frac{1}{2} b+\frac{1}{2} ; 3 / 2 ;(1-2 x)^{2}\right\} .
\end{aligned}
$$

The tables give $G_{1}(x), G^{\prime}{ }_{1}(x), G_{2}(x), G^{\prime}{ }_{2}(x)$, for $x=[0(.01) .5 ; 6$ or $7 \mathrm{~S}]$.

There are also tables, with 6 or $7 \mathrm{~S}$, for the deflection and stress coefficients which are computed by numerical integration from the functions $G_{1}(x), G_{2}(x)$, and two auxiliary functions $H_{1}(x), H_{2}(x)$. The $H$-functions are called "subtracting off" functions and are chosen so that the differences, $G_{n}(x)-H_{n}(x)$ are bounded uniformly throughout the interval of existence of $G_{n}(x)$. Some intelligence is used in the choice of these functions.

H. B.

221[L].-N. Karsmenkov in Herbert Buchholz, "Die konfluente hypergeometrische Funktion mit besonderer Berücksichtigung ihrer Bedeutung für die Integration der Wellengleichung in den Koordinaten eines Rotationsparabolö̈des," Z. angew. Math. Mech., v. 23, 1943, p. 106-108, 117. $21.6 \times 27.8 \mathrm{~cm}$. 
This is a continuation of a former paper, p. $47-58$, in which definitions are given of wave-functions $m_{i \tau}^{(p)}(i \zeta), w_{i \tau}^{(p)}(i \zeta)$ suitable for the treatment of problems connected with a paraboloid of revolution. The relation between $m_{i \tau}^{(p)}(i \zeta)$ and Whittaker's confluent hypergeometric function $M_{k, m}(z)$ is

$$
m_{i \tau}^{(p)}(i \zeta)=\left[\frac{1}{2} \pi /(i \zeta)\right]^{!} M_{i \tau, \frac{1}{2} p}(i \zeta)
$$

The tables on p. 106 give from 4 to $7 \mathrm{~S}$ for

$$
(2 / \pi)^{\frac{1}{3}} m_{i \tau}^{(0)}(i \zeta)
$$

for $\tau=-3(.5) 3$ and $\zeta=1(1) 6$. Those on p. 107 give from 5 to $7 \mathrm{~S}$ for

$$
(2 / \pi)^{\frac{1}{\partial} \partial m_{i \tau}^{(0)}(i \zeta) / \partial \zeta}
$$

for the same ranges. On p. 106 there is also a short table of the smallest root $\tau_{1}$ of the equation

$$
m_{i \tau}^{(0)}(i \zeta)=0
$$

to $5 \mathrm{D}$ for $\zeta=0(1) 6$ and $\zeta=4.80966$ when $\tau_{1}= \pm 0$. A diagram gives a perspective representation of $M_{i \tau, 0}(i \zeta) /(i \zeta)^{\frac{1}{3}}$ for $-3<\tau<2,0<\zeta<6$. On p. 107 there is a perspective representation of the function

$$
\frac{\partial\left[M_{i \tau, 0}(i \zeta) /(i \zeta)^{\natural}\right]}{\partial \zeta}
$$

for $\tau=0$ to $3, \zeta=0$ to 6. On p. 108 there is a short table of the first three zeros $\tau^{\prime}{ }_{1}, \tau^{\prime}{ }_{2}, \tau^{\prime}{ }_{3}$ of $m_{i \tau}^{\prime(0)}(i \zeta)$. The computations were made by N. KARSMENKov who also drew the diagrams. Among the asymptotic formulae that are given, mention may be made of one for

$$
(i \zeta)^{-j(p+1)} M_{i \tau,\} p}(i \zeta)
$$

when $\zeta<0$ and $\tau$ is large and positive, a series for $2 \sqrt{\left|\tau_{n} \zeta\right|}$ in descending powers of $j_{0 n}$, where $J_{0}\left(j_{0 n}\right)=0$, asymptotic formulae for $M_{\nu, j p}(z)$ and $W_{\nu, j p}(z)$ as $z \rightarrow \infty, \nu \rightarrow \infty$ and as $p \rightarrow \infty$, some of these being due to Whittaker and Erdélyi. Orthogonal relations are given, one of which is claimed to be new as the arguments' of the functions $m_{i \tau_{n}}^{(p)}(i \zeta)$ are imaginary. It is thought that the series, asymptotic formulae and orthogonal functions given in the paper represent a decisive step forward towards the solution of the practically important problems relating to the paraboloid of revolution. A good bibliography is given (p. 117) but in the light of some information about what is being done in this country the list is far from complete.

H. B.

222[L].-Murlan S. Corrington \& William Miehle, "Tables of Bessel functions $J_{n}(x)$ for large arguments," $J$. Math. Physics, M.I.T., v. 24, Feb. 1945 , p. $30-50.17 .4 \times 25.5 \mathrm{~cm}$.

Five-place tables of $J_{n}(m s)$ are here given for $n=0(1) 10, s=1(1) 20$, and (a) $m=1(1) 10$; (b) $m=\pi(\pi) 5 \pi$. Also for $m=1$ and $\pi, n=0(1) 10, s=21(1) 40$. These are the tables to which earlier reference was made in their unpublished form, $M T A C$, p. 285.

The values of $J_{n}(s), n=1(1) 10, s=1(1) 21$ were obtained by rounding off the 18-place values of Meissel, published in A. Gray \& G. B. Mathews, $A$, Treatise on Bessel Functions, London, 1895; second ed. 1922. For higher values of the argument the values were all computed from the asymptotic formula. The auxiliary functions $A_{0}(x), B_{0}(x), A_{1}(x), B_{1}(x)$, and their tabulations (see $M T A C$, p. 282), were used when possible. Tabular values were computed to $7 \mathrm{D}$ or $8 \mathrm{D}$, and later rounded off to $5 \mathrm{D}$. "Where there was any reasonable doubt as to whether to add or drop a half, the function was recalculated more accurately." As a further check comparison was made with the following known tables: (a) H. NAGAOKA, Tokyo, College of Science, J., v. 4, 1891, where there is a table of $J_{0}(n \pi), n=[1(1) 50 ; 6 \mathrm{D}]$; a 5-place abridgement is in K. HAYASHI, Fünfstellige Funktionentafeln . . ., Berlin, 1930; no errors were found. See $M T A C$, p. 299. (b) Values of $J_{n}(20), J_{n}(30), J_{n}(40), J_{n}(50)$, 
$J_{n}(100), n=0,1$, are given in K. HAYASHI, Tafeln der Besselschen, Theta-, Kugel-, und anderer Funktionen, Berlin, 1930; the statement of the paper under review in this connection is incorrect. See $M T A C$, p. 291. (c) L. STEINER, Math. naturw. Berichte aus Ungarn, v. 11, 1894, which has a table of $J_{1}(x), x=[20.1(.1) 31(.2) 41 ; 6 \mathrm{D}]$; on comparing the values for integral argument no discrepancies were found. See $M T A C$, p. 305.

"The mathematical theory of frequency-modulated radio broadcasting shows that the sideband amplitudes of a carrier modulated with sinusoidal variations in frequency are proportional to the Bessel functions of the first kind $J_{n}(m)$, where $n$ is the sideband number and $m$ is the modulation index. Since $m$ equals the maximum deviation in frequency, $D$, divided by the audio frequency $\mu$, it is evident that at the lower audio frequencies the ratio $D / \mu$ can become quite large. This means that in order to determine the sideband amplitudes it is necessary to use tables of Bessel functions for large values of the argument $m . "$

R. C. A.

223[L].-H. R. F. Carsten \& Miss N. W. McKerrow, "The tabulation of some Bessel functions $K_{\nu}(x)$ and $K_{\nu}{ }^{\prime}(x)$ of fractional order," Phil. Mag., s. 7, v. 35, Dec. 1944 , p. $816-818.17 .1 \times 25.5 \mathrm{~cm}$.

"Under certain conditions, the temperature field within a cylindrical rod, subjected to a sudden change in temperature, may be developed in terms of modified Bessel functions of the second kind, of order $n \pm \frac{1}{4}$, and their derivatives. As values of such functions do not yet appear to have been published, it has been found desirable to prepare tables of these for a range of the variables." Here are tables of $K_{1}(x), K_{3 / 2}(x), K_{5 / 2}(x), K_{1 / 4}(x), K_{3 / 4}(x)$, $-K_{1 / 4}^{\prime}(x),-K_{3 / 4}^{\prime}(x), x=[.1(.1) 5,6(2) 10 ;$ mostly $5 \mathrm{~S}] . K_{\xi}(x)=(\pi / 2 x)^{3} e^{-x}=\lambda ; K_{3 / 2}(x)$ $=\lambda[1+1 / x] ; K_{5 / 2}(x)=\lambda\left[1+(3 / x)+3 / x^{2}\right]$. Then $K_{1 / 4}(x), K_{3 / 4}(x)$ were computed by Lagrange's interpolation formulae from values of $K_{0}, K_{1}, K_{2} \cdots$, tabulated in G. N. Watson, Theory of Bessel Functions, second ed, 1944, p. 737, and from previously calculated $K_{1 / 2}(x), \quad K_{3 / 2}(x) \cdots . \quad K_{1 / 4}^{\prime}(x)=-1 /(4 x) K_{1 / 4}(x)-K_{3 / 4}(x), \quad K_{3 / 4}^{\prime}(x)=-3 /(4 x) K_{3 / 4}(x)$ $-K_{1 / 4}(x)$.

224[L].-K. FRÄNZ \& T. Vellat, "Der Einfluss von Trägern auf das Rauschen hinter Amplitudenbegrenzern und linearen Gleichrichtern," Elek. Nach. Tech., v. 20,1943, p. 185, 188-189. $21.5 \times 28 \mathrm{~cm}$.

The calculations in this paper depend on confluent hypergeometric functions, and a table gives $C_{n}(x)$, for $n=[1(1) 13,15 ; 4 \mathrm{~S}]$, with graphs, and $\sum_{n=1}^{15} C_{n}(x)$, to $3 \mathrm{~S}$, and $x=0, .1$, $.15, .25, .4, .6,1,1.5,2.5,4,6,10$, where

$$
C_{n}(x)=(1 / 4 \pi) \sum_{k=0(1) n}^{\infty} \frac{x^{2 n-4 k-2} \Gamma^{2}\left(n-k-\frac{1}{2}\right)_{1} F_{1}^{2}\left(n-k-\frac{1}{2} ; n-2 k ;-x^{2}\right)}{(k !)(n-k) ![(n-2 k-1) !]^{2}} .
$$

H. B.

225[L].-C. TRUESDELl, "On a function which occurs in the theory of the structure of polymers," Annals Math., s. 2, v. 46, Jan. 1945, p. 150. $17.5 \times 25.3 \mathrm{~cm}$.

Appell's integral is defined as

$$
\phi(x, s)=\frac{x}{\Gamma(s)} \int_{0}^{\infty} \frac{t^{s-1} d t}{e^{t}-x} .
$$

The tables are for the functions $\phi\left(x,-\frac{1}{2}\right), \phi\left(x, \frac{1}{2}\right), \phi(x, 3 / 2), x=[.05(.05) .95(.01) .99$, $.995(.001) 1 ; 4 \mathrm{~S}]$, and are correct to $4 \mathrm{~S}$ except in the ranges: for $\phi\left(x,-\frac{1}{2}\right), .45 \leqq x \leqq .80$; for $\phi\left(x, \frac{1}{2}\right), .65 \leqq x \leqq .97 ;$ for $\phi(x, 3 / 2), .75 \leqq x \leqq .999$. In these ranges the tables are correct to within \pm .001 . 
226[L].-[F. VAndrey], Great Britain, Department of Scientific Research and Experiment, Admiralty Computing Service, Tables of Legendre Functions $Q_{n}(x)$, London, February, 1945, 2 p. text and 2 p. tables. No. SRE/ACS65. $21.5 \times 34.3 \mathrm{~cm}$. Mimeographed. This edition of these tables is available only to certain Government agencies and activities.

In $M T A C$, p. 190, appears a review of tables, 1940, computed by F. VANDREy, of the Legendre Function of the second kind, for $n=0(1) 7$, and for $x=[0(.01) 1 ; 5 \mathrm{D}]$. The present publication is a reprint of these tables with the following corrections:

$$
\begin{aligned}
& Q_{2}(x), x=.82, \text { for }-0.64134, \text { read }-0.64164 \\
& Q_{7}(x), x=.51, \text { for }-0.31312, \text { read }-0.31316 \\
& Q_{6}(x), x=.99, \text { for }+0.03725, \text { read }-0.03725 \\
& Q_{7}(x), x=.99, \text { for }-0.07590, \text { read }-0.21288
\end{aligned}
$$

"The differences suggest that the last figure given [in the tables] is probably not more than 1 or 2 units in error."

There is a table of $2 Q_{n}(x), n=1(1) 8$, for $x=[0(.01) 1 ; 4 \mathrm{D}]$ in H. TAllqvist, Grunderna af Teorin för Sferiska Funktioner, jämte Användningar inom Fysiken, Helsingfors, 1905, p. $401-407$.

227[L, M].-A. H. A. HogG, "Equilibrium of a thin slab on an elastic foundation of finite depth," Phil. Mag., s. 7, v. 35, Apr. 1944, p. 270-275. $17 \times 25.4 \mathrm{~cm}$.

There are tables, to $4 \mathrm{D}$, for the definite integrals

$$
\begin{aligned}
& (1 / 2 \pi x) \int_{0}^{\infty} J_{1}(m x) F(m) m d m, \quad b=0(.1) 1, \\
& \left(b^{2} / 2 \pi x^{2}\right) \int_{0}^{\infty} J_{0}(m x) F(m) d m, \quad b=0(.1) 1,2, \\
& \left(1 / 2 \pi x^{2}\right) \int_{0}^{\infty}\left[m x^{2} J_{1}(m x)-m^{2} x^{2} J_{0}(m x)\right] F(m) d m, \quad b=0(.1) 1,
\end{aligned}
$$

where

$1 / F(m)=m^{3}+(b / x)^{3}\left[(\sinh m \cosh m+m t) /\left(\sinh ^{2} m-m^{2} t^{2}\right)\right], t=1 /(3-4 \sigma)$. The values of Poisson's ratio $\sigma$ used in the tables are $.3, .4, .5$.

H. B.

228[L, M].-C. P. Wells \& R. D. Spence, "The parabolic cylinder functions," J. Math. Phys., M.I.T., v. 24, Feb. 1945, p. 51-64. $17.5 \times 25.3$ cm.

The tables, p. 60-61, give the functions ${ }_{e} U_{a}(x),{ }_{o} U_{a}(x)$ for the ranges $a=-3(1)-1$, $1(1) 3, x=[0(.1) 3 ; 4 \mathrm{D}]$. Then follows a table of $\Gamma\left(\frac{3}{4}+\frac{1}{4} i a\right), a=1(1) 5$. Graphs are given (p. 62-63) and the first and second roots of ${ }_{e} U_{a}(x)=0$ and ${ }_{o} U_{a}(x)=0$ are shown in a figure on p. 64 .

Formulae for ${ }_{e} U_{a}(x),{ }_{o} U_{a}(x)$ are given on p. 51-59. Particular values are

$$
{ }_{e} U_{o}(x)=\Gamma\left(\frac{3}{4}\right)\left(\frac{1}{2} x\right)^{1 / 2} J_{-1 / 4}\left(\frac{1}{2} x^{2}\right), \quad{ }_{0} U_{o}(x)=\Gamma\left(\frac{5}{4}\right)(2 x)^{\frac{1}{3}} J_{1 / 4}\left(\frac{1}{2} x^{2}\right) .
$$

The formulae of $\mathrm{H}$. Weber are written in the convenient form

$$
\begin{aligned}
& { }_{e} U_{a}(x)={ }^{3} c_{1} \int_{0}^{\infty}(\operatorname{sech} u)^{\frac{1}{2}} \cos \left(\frac{1}{2} x^{2} \tanh u+\frac{1}{2} a u\right) d u, \\
& { }_{0} U_{a}(x)=2^{-3 / 2} c_{2} \int_{0}^{\infty}(\operatorname{sech} u)^{3 / 2} \cos \left(\frac{1}{2} x^{2} \tanh u+\frac{1}{2} a u\right) d u,
\end{aligned}
$$

where $c_{1}, c_{2}$ are determined so that ${ }_{e} U_{a}(0)=1,{ }_{o} U_{a}^{\prime}(0)=1$.

H. B. 
229[M].-Georges Goudet \& Miss A. M. Gratzmuller, "Divergence par l'effet de la charge d'espace d'un faisceau électronique cylindrique non accéléré," J. d. Physique et le Radium, s. 8, v. 5, July 1944, p. 144-147. $21.5 \times 28 \mathrm{~cm}$.

$$
\begin{gathered}
f(x)=4 \int_{0}^{1}\left[\sinh ^{-1}\left(\frac{x}{\sqrt{2} \sqrt{1-\sqrt{1-u^{2}}}}\right)-\sinh ^{-1}\left(\frac{x}{\sqrt{2} \sqrt{1+\sqrt{1-u^{2}}}}\right)\right] d u, \\
\phi_{\alpha}(x)=E_{0} / R \rho=\frac{1}{2}[f(x)-f(\alpha-x)], \psi(\alpha)=\alpha \int_{0}^{1 / 2 \alpha} \phi_{\alpha}(u) d u .
\end{gathered}
$$

There are tables of $f(x), x=[0(.1) 10(1) 80 ; 3-4 \mathrm{~S}] ; \phi_{\alpha}(x), \alpha=.5(.5) 5,7,10,20, x / \alpha$ $=[0(.1) .5 ; 3 \mathrm{~S}] ;$ and of $\psi(\alpha), \alpha=[0(.1) 2.5,2.8(.2) 3.2,3.5,3.6(.4) 4.4,4.5,4.8(.2) 5.2(.4)-$ $6.8(.2) 7.2,8(1) 20 ; 2-4 \mathrm{~S}]$. There are graphs of $f(x), 0<x<2.5$; of $\phi_{\alpha}(x)$ for the 13 values of $\alpha, 0<x / \alpha<.5$; and of $\psi(\alpha)$.

230[U].-Akademîâ Nauk. S.S.S.R., Leningrad, Matematicheskir Institut imeni V. A. Steklova, Tablitsy dlia opredeleniıa linii polozheniia korablia po radiopelengu. [Tables for the determination of the line of position of a ship by radio bearings.] Moscow and Leningrad, Academy of Sciences, 1944,137 p. + errata slip. $12.7 \times 20 \mathrm{~cm} .10$ roubles. 1000 copies in the edition.

These tables permit the rapid determination of lines of position from radio bearings of radio stations within 270 nautical miles of the observer, in latitudes $80^{\circ} \mathrm{S}$ to $80^{\circ} \mathrm{N}$. They were prepared by the Mathematical Institute of the Academy of Sciences, on the request of the Nauchno-ispytatel'nyi Hidrografichesko-shturmanskii Institut [Scientific-experimental Pilot Institute]. The basic ideas are credited to L. A. LIÚSTERnIK, D. A. VASIL'Kov and I. Fa. Akushskir. The computations were carried out by calculating machine at the Institute; it is stated that bearings calculated by the method will be correct to within $15^{\prime}$. Since bearings determined by radio-direction-finding apparatus available for general use before the war were usually given to the nearest degree, and of ten were in error by several degrees, especially when the sunrise or sunset line lay between the radio station and the observer, the tables would appear to provide ample accuracy.

The book is quite small and convenient to use. Only a single multiplication is required and that could be carried out by slide rule. The paper used in the volume reminds one that it is a war-time product.

In the use of the tables, one starts with an assumed position, $P_{0}$, which is chosen in such a way that $\Delta \lambda, \Delta \phi$, the differences in longitude and latitude between this position and that of the radio station are integral numbers of degrees. One then seeks in the table the tabular latitude nearest that of the radio station, and with $\Delta \lambda, \Delta \phi$ as additional arguments, takes out $A_{c}$, the computed bearing; $i$, a correcting angle; and $k$, a differential coefficient to be used in allowing for the difference between the observed and computed bearings, $A-A_{c}$. The line of position can then be laid off in such a way that it makes an angle, $T=A_{c}+i \pm 90^{\circ}$ with the local meridian, and that it lies at a perpendicular distance, $k\left(A-A_{c}\right)$ nautical miles from $P_{0}$. Rules are given for deciding the side of $P_{0}$ on which the line is to be drawn.

The trigonometric relations used in preparing the tables are:

$$
\begin{aligned}
\cot A_{c} & =\tan \phi_{0} \cos \phi_{c} \csc \Delta \lambda-\sin \phi_{c} \cot \Delta \lambda, \\
\tan i & =\sin \phi_{c} \tan \Delta \lambda, \\
k & =\sin i /\left(\tan A_{c} \tan \phi_{c}\right),
\end{aligned}
$$

where $\lambda_{0}, \phi_{0}$ are respectively the assumed longitude and latitude of the observer, $\lambda_{c}, \phi_{c}$ are the longitude and latitude of the radio station and $\Delta \lambda=\lambda_{0}-\lambda_{c}$.

It is interesting to note that the tabulated values of latitude are not evenly spaced, nor are they integral degrees; for example, $0^{\circ} 00^{\prime}, 3^{\circ} 25^{\prime}, 6^{\circ} 50^{\prime}, 10^{\circ} 15^{\prime}, 12^{\circ} 49^{\prime}, 15^{\circ} 13^{\prime}$, $17^{\circ} 16^{\prime}, \cdots, 60^{\circ} 05^{\prime}, 60^{\circ} 30^{\prime}, 60^{\circ} 55^{\prime}, 61^{\circ} 10^{\prime}, 61^{\circ} 35^{\prime}, \cdots, 79^{\circ} 33^{\prime}, 79^{\circ} 40^{\prime}, 79^{\circ} 47^{\prime}, 79^{\circ} 54^{\prime}$. 
The values of $\Delta \lambda$ range from $1^{\circ}$ to $28^{\circ}$; and $\Delta \phi$ from $-5^{\circ}$ to $+5^{\circ}$ for $\phi=0, \Delta \lambda=1^{\circ}$; to $-1^{\circ}$ to $+1^{\circ}$ for $\phi=79^{\circ} 36^{\prime}, \Delta \lambda=28^{\circ}$.

Brown Univ.

C. H. SMILEY

231[U].-Great Britain, H. M. Nautical Almanac Office, Astronomical

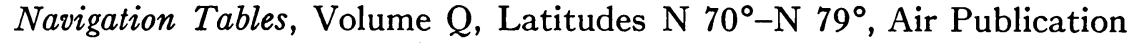
1618. London, H. M. Stationery Office, 1945 , iv, 341 p. $16.5 \times 24.8 \mathrm{~cm}$. These tables are available only to certain Government agencies and activities.

This is the fifteenth and last volume in the series of no. 1618 which has had restricted circulation in this country by the Hydrographic Office, under the number H. O. 218. We have already reviewed the earlier volumes, $M T A C$, p. 82f, each one covering five degrees of latitude, v. A, $0^{\circ}-4^{\circ}$ (no volume lettered I or 0 ) to v. $\mathrm{P}, 65^{\circ}-69^{\circ}$, the fourteenth. The present volume covering $10^{\circ}$ is naturally the largest, and is applicable between latitudes $69^{\circ} 30^{\prime}$ and $79^{\circ} 30^{\prime}$ north for specially selected stars, and both north and south for the rest of the volume.

R. C. A.

232[U].-SAmuel Herrick, "The air almanac refraction tables," U. S. Naval Inst., Proc., v. 70, Sept. 1944, p. 1140-1141. $17 \times 25.5 \mathrm{~cm}$.

In this note Herrick shows how, by graphical representation, the advantages of critical tables can be had in the case of double-entry tables. As illustrations, he chose the tables for total refraction and refraction adjustment as given in the American Air Almanac. With height above sea level in feet, and observed altitude in degrees as the ordinate and abscissa respectively, one reads the total refraction (or refraction adjustment) directly from the appropriate graph. Herrick constructed his graphs from data in L. J. Comrie, Hughes' Tables for Sea and Air Navigation (see MTAC, p. 111) and notes that there is a slight discrepancy between the figures given by Comrie and those presented by the American Air Almanac.

C. H. Smiley

\section{MATHEMATICAL TABLES-ERRATA}

References have been made to Errata in RMT 216 (N.D.R.C.), 217 (Chebyshev), 222 (Corrington \& Miehle), 226 (Vandrey); N 43 (Euler, Legendre, Newman, Powell); QR 18 (Hayashi, Roman).

67. James Burgess, "On the definite integral $\left(2 / \pi^{\frac{1}{3}}\right) \int_{0}^{t} e^{-t^{2}} d t$, with extended tables of values," R. So. Edinburgh, Trans., v. 39, 1898, p. 321. In MTE 62, $M T A C$, p. 429 there was a reference to the present additional list of errors in Burgess' table.

The test of the values of $L$ was based on the relation $L=t \sqrt{2} \cdot F(t \sqrt{2})$, where $F(x)$ is the function tabulated to $24 \mathrm{D}$ in W. F. Sheppard, The Probability Integral, T. II (BAASMTC, v. 7, Cambridge, Univ. Press, 1939). My interpolations were all based on $18 \mathrm{D}$ of $F(x)$ and its reduced derivatives, while all multiples of $\sqrt{2}$ were carried to $20 \mathrm{D}$. Consequently, the final values of $L$ should be correct to $17 \mathrm{D}$. As an additional check the values of $L$ in the interval $3.0 \leqq t \leqq 5.0$ were differenced repeatedly until 14th differences were reached. This procedure failed to reveal any errors other than those unavoidably committed in curtailing the results. For $t=5.5$ and 6.0 the values were checked by a second calculation.

Thus it was discovered that the following 13 of the 24 L-entries comprising this table of Burgess are in error, some quite seriously: 